\title{
As doenças e o controle dos desejos corporais dos meninos recolhidos em instituições educativas maranhenses no oitocentos
}

Diseases and control of bodily desires of boys kept in educational institutions of Maranhão, Brazil in the eighteen hundreds (nineteenth century)

Las enfermedades y el control de los deseos corporales de los niños recogidos en instituciones educativas maranhenses en los ochocientos

\author{
Cesar Augusto Castro ${ }^{1}$ \\ SAMUEl Luis VelazQuez CASTEllanos ${ }^{2}$
}

\section{Resumo:}

Estudo sobre os aspectos médicos-sanitários e do comportamento sexual dos alunos da Escola de Aprendizes Marinheiros, da Escola Agrícola do Cutim e da Casa dos Educandos Artífices. Instituições asilares instaladas no Maranhão no período oitocentista e que tinham a finalidade de atender crianças pobres e desvalidas. Como fonte de análise, utilizou-se a pesquisa documental, tomando como referência os relatórios dos médicos Silva Maia e César Augusto Marques. Os relatórios noticiavam as doenças que acometiam aos educandos tratados nas enfermarias criadas no interior desses estabelecimentos, no Hospital da Santa Casa da Misericórdia ou no Hospital Militar. Além dessas fontes, recorreram-se às correspondências dos diretores dessas instituições, onde foi possível identificar aspectos que evidenciam as causas das doenças e o comportamento sexual dos meninos de diferentes idades entre si. A partir desse estudo, identificaram-se as principais doenças que os acometiam; as regras de controle; as punições e as permissões dadas a esses rapazes para se deitarem com pessoas do mesmo sexo ou com o sexo oposto, e as formas de controlar e tratar as doenças.

Palavras-chave: Período oitocentista. Maranhão. Instituições asilares. Enfermidades. Comportamento sexual.

\footnotetext{
${ }^{1}$ Doutor em Educação pela Universidade de São Paulo, com estágios de pós-doutorado realizados na Universidade de São Paulo e na Universidade do Porto. Bolsista de Produtividade em Pesquisa do CNPq. Professor Titular da Universidade Federal do Maranhão integrando o Programa de Pós-graduação em Educação e o Curso de Biblioteconomia. Coordenador do Núcleo de Estudos e Documentação em História da Educação e Práticas Leitoras (NEDHEL). Professor colaborador do Programa de Pós-Graduação em Educação da Universidade Federal do Pará. Representante da região nordeste na Sociedade Brasileira de História da Educação. E-mail: ccampin@terra.com.br

${ }^{2}$ Doutor em Educação Escolar pela Universidade Estadual Paulista Júlio de Mesquita Filho, com estágio de pós-doutorado realizado no Centre d'Histoire Culturalle des Sociétés Contemporaines da Université de Versailles, na França. Bolsista Produtividade da Fapema. Professor Associado do Programa de Pós-Graduação em Gestão de Ensino da Educação Básica e do Departamento de Educação I da Universidade Federal do Maranhão. Membro da Associação para a Pesquisa sobre o Brasil na Europa e da Association pour le Développement de l'Histoire Culturelle.E-mail: samuel@ufma.br
} 


\begin{abstract}
:
Study on the medical and health aspects and on the sexual behavior of students of the School for Sailors, Cutim Agricultural School and Craftsmen Student House. Asylums installed in Maranhao in nineteenth-century period and were meant to serve the poor and underprivileged children. As a source of analysis, it was used to document research with reference to the reports of doctors Silva Maia and César Augusto Marques. The reports informed about the diseases affecting the students treated in the wards created inside these establishments, in the Santa Casa da Misericordia Hospital or the Military Hospital. Besides these sources, turned up the correspondences of the directors of these institutions, where it was possible to identify aspects that highlight the causes of diseases and the sexual behavior of young people. From this study, we identified the major diseases affecting students; control rules; punishment; and permissions given to these young boys to lie with people of the same sex or the opposite sex, and ways to control and treat diseases.
\end{abstract}

Keywords: Nineteenth-century period. Maranhão. Asylums. Diseases. Sexual behavior.

\title{
Resumen:
}

Estudio sobre los aspectos médicos-sanitários y del comportamiento sexual de los alumnos de la Escuela de Aprendizes Marineros, de la Escuela Agrícola del Cutim y de la Casa de los Educandos Artifices. Instituciones asilares instaladas en Maranhão en el periodo ochocentista que tenían la finalidad de atender a niños pobres y desvalidos. Como fonte de análisis, se utilizó la investigación documental, tomando como referencia los relatorios de los médicos Silva Maia y César Augusto Marques. Los relatorios noticiavan las enfermedades que castigaban a los educandos tratados en las enfermerias creadas en el interior de esos establecimientos, en el Hospital de la Santa Casa de la Misericordia o en el Hospital Militar. Además de esas fuentes, se recorrieron as las correspondencias de los directores de esas instituciones, donde fue posible identificar aspectos que evidencian las causas de las enfermedades y del comportamiento sexual de los niños de diferentes edades entre si. A partir de ese estudio, se identificaron las principales enfermedades que los acometían; las reglas de control; las puniciones y las permisiones dadas a esos niños para que se acostaran con personas del mismo sexo o con el sexo opuesto, y las formas de controlar y tratar las enfermedades.

Palabras clave: Periodo ochocentista. Maranhão. Instituciones asilares. Enfermedades. Comportamiento sexual. 


\section{Introdução}

Neste trabalho, tratamos dos aspectos médicos-sanitários e do comportamento sexual dos meninos recolhidos em três instituições asilares na Província do Maranhão: a Escola de Aprendizes Marinheiros $^{3}$, a Escola Agrícola do Cutim $^{4}$ e a Casa dos Educandos Artífices ${ }^{5}$. Essas instituições tinham a finalidade de atender crianças pobres e enjeitadas ${ }^{6}$, e dar-lhes uma profissão e o ensino das primeiras letras. O interesse por este assunto deu-se pela presença, mesma que lacunar, de documentos, como os relatórios dos médicos Silva Maia e César Augusto Marques, sobre as doenças que acometiam aos educandos tratados nas enfermarias criadas no interior desses estabelecimentos, no Hospital da Santa Casa da Misericórdia ou no Hospital Militar. Entre as doenças mais frequentes elencam-se as febres intermitentes, diarreias, vermes e doenças venéreas, como bubões, sífilis ${ }^{7}$ e cancro mole ${ }^{8}$. Além dessas fontes, as correspondências dos diretores dessas instituições evidenciavam as doenças e o comportamento sexual dos jovens entre si, que mantinham relações homossexuais ou com mulheres, as quais viviam "para aliviar a natureza dos homens", como assim se referia Antonio Falcão (RELATÓRIO..., 1842) quando falava das prostitutas.

A partir dessas fontes, levantamos algumas questões, que nos pareceram pertinentes de serem respondidas, a partir do que nos foi dado a ver pela massa de documentos que se encontram no Arquivo Público do Estado do Maranhão: Quais as doenças que acometiam aos educandos? Quais as regras de controle, punição e permissividades dadas a esses rapazes, para se deitarem com pessoas do mesmo sexo ou do sexo oposto? Como se estabeleciam esses encontros? Quais foram as formas de tratamento das doenças? No caso das relações de "[...] inversão dos papeis sexuais e a relação entre indivíduos do mesmo sexo" (FOUCAULT, 2007, p. 21), as fontes são mais escassas, na medida em que este tema, no século XIX, precisava ser mantido sob uma névoa escura e impenetrável (REVENIN, 2013), apesar de sua frequência nessas instituições, regidas pelos

\footnotetext{
${ }^{3}$ A Escola de Aprendizes Marinheiros foi criada pelo Decreto $\mathrm{n}^{\circ} .2725$ de 12 de janeiro de 1861, quando Francisco Xavier Pais Barreto era Ministro da Marinha. Sob o comando do $1^{\circ}$ Tenente da Armada José Francisco Pinto, a escola alojou grande número de meninos pobres e desvalidos, que aprendiam as primeiras letras e as artes mecânicas necessárias para o desenvolvimento da navegação pelos rios maranhenses, como o Itapecuru, o Mearim, o Corda, entre outros.

${ }^{4}$ Criada em 7 de abril de 1854, durante o governo de João Lustosa da Silva Paranaguá, localizado junto ao Riacho Cutim, com a finalidade de recolher crianças do sexo masculino e ensinar-lhes ofícios atinentes ao cultivo da terra e à criação de animais.

5 Criada em 1841 com a finalidade de recolher crianças do sexo masculino e dar-lhes uma educação profissional de sapateiro, carpinteiro, marceneiro, etc.

${ }^{6}$ Enjeitada nesse trabalho entende-se "aquele que foi abandonado pelos pais" (FIGUEIREDO, Candido de. Novo Dicionário da língua portuguesa. Lisboa: Tavares Cardoso e Irmão, 1899.v. 2.

${ }^{7} \mathrm{Na}$ documentação, esta doença aparece com as seguintes denominações: mal-gálico e pudendagra.

${ }^{8}$ Popularmente também conhecida como cavalo.
} 
preceitos da religião, do discurso médico, com a sua postura higienista e, do discurso jurídico, no caso da resistência e da reincidência (MOREIRA, 2012). Sobre este assunto, localizamos casos de professores, capitães do porto e educandos mais velhos que se valiam do poder que exerciam para submeter aos menores os seus caprichos e desejos carnais; práticas que Foucault (2007) conceitua de "formas de sujeição".

Essa relação do poder dos mais fortes sobre os mais frágeis era uma maneira de colocar o “[...] outro numa posição de fraqueza, física ou mental”, próprio das "personalidades autoritárias" (HAROCHE, 2013, p. 29). Essas características das relações de poder eram comuns a todos os diretores dessas instituições, que em nome do controle e da manutenção da ordem, dada pelo lugar e pela posição que ocupavam, submetiam aos alunos a um forte esquema de esquadrilhamento do tempo, do espaço e dos movimentos corporais (FOUCAULT, 2002). Para que esse aparelho disciplinar funcionasse, foram formuladas leis e regulamentos que regiam o comportamento, as formas de punição, as premiações e, principalmente, a ocupação física dos meninos de modo a anular "[...] tudo o que [pudesse] perturbar e distrair; tra[tando]-se de constituir um tempo integralmente útil (FOUCAULT, 2004, p. 46). Desse modo, evitava-se que os meninos se distraíssem com atividades pouco úteis às suas formações física e moral, dentre as quais os desejos do corpo, considerados como incompatíveis com a "[...] formação de um jovem para os trabalhos manuais que tanto a província care[cia]", como se reporta Antonio Maia (diretor dos educandos artífices), ao tratar em seu relatório (1867) do crescente número de doenças venéreas entre os alunos dessa instituição. Identificamos, também, nas fontes, casos de jovens que subvertiam as ordens dos seus superiores para saírem com mulheres e "terem" momentos furtivos de amor. Outro dado é de que o próprio diretor da Escola Agrícola do Cutim, Luiz Clemont ${ }^{10}$, toda noite abandonava o estabelecimento, sob a sua responsabilidade, para beber e encontrar-se com senhoras nas casas de rendez-vous no centro da cidade de São Luís. Segundo Farge (2013, p. 516):

Os espaços ordinários onde os homens e as mulheres da cidade se reúnem, acentuam, sem nenhuma dúvida, a rudeza dos comportamentos viris: o cabaré é um dos lugares principais onde se praticam as piadas de mau gosto, onde ocorrem as grosserias, onde os homens param para beber e firmar contratos de trabalhos. Neles, a bebedeira é a companheira habitual: todo incidente se dramatiza, geralmente entre a escolha de uma companheira, crescendo a vaidade entre os homens que dispunham sobre quem vai subir no quarto com a mais desejada.

\footnotetext{
${ }^{9} \mathrm{O}$ verbo "ter" é muito utilizado nos documentos para expressar as relações sexuais dos alunos.

${ }^{10}$ Agrônomo contratado na França para dirigir a Escola Agrícola do Cutim.
} 
Entretanto, este texto, mesmo limitado pelas fontes, traz evidências e possibilidades para entendermos que no interior dessas instituições, apesar de todo um controle pela "moralidade dos comportamentos" (FOUCAULT, 2007, p. 26), corpos eram acometidos de inúmeras doenças, oriundas das condições climáticas do Maranhão, como as constipações e febres de quebra ossos, por diferentes epidemias (beribéri, sarampo e varíola) e por aquelas moléstias, fruto das relações sexuais “'lícitas' (normativo e tolerável) ou 'ilícitas' (desviante e intolerável)" (MATTHEWS-GRIECO, 2008, p. 220).

\section{Moléstias e tratamentos sanitários dos educandos maranhenses}

Desde a fundação dessas instituições, foi estabelecido um conjunto de procedimentos médicos-sanitários para garantir a saúde física e mental dos meninos recolhidos, como quartos de dormir, com amplas janelas para a entrada da luz e da ventilação natural; chão de madeira ou atijolado, para evitar o contato com "piso de chão batido". Essas instituições deveriam funcionar em prédios construídos ou adaptados, longe de lugares que, durante o período das chuvas, pudessem concentrar águas e afastados dos fluxos das marés. Além disso, em cada um desses estabelecimentos, foram criadas enfermarias para receber os doentes e uma horta com plantas medicinais, como boldo, agrião, capim-limão, pau-de-índio e outras que pudessem tratar as indisposições simples dos meninos, professores e pessoal administrativo. Os casos mais graves eram removidos para o Hospital Militar e/ou o Hospital da Santa Casa da Misericórdia, onde recebiam atendimento gratuito do seu corpo médico, com exceção dos medicamentos da "botica", que eram garantidos pelas finanças dessas repartições de ensino.

No caso da Enfermaria da Casa dos Educandos Artífices, apesar de ter sido regulamentada em 1843, somente em 1855, na gestão de Antonio Maia, foi instalada no interior do estabelecimento para atender com chás, unguentos e alguns medicamentos as enfermidades, como febres intermitentes, verminoses e constipações, sob a atenção dos alunos mais velhos, que cuidavam desse "quarto de saúde" “[...] depois que haviam sido orientados para essas atividades pelo médico César Augusto Marques” (RELATÓRIO..., 1855).

No caso de doenças mais graves, os enfermos eram encaminhados para o hospital da Santa Casa, ou eram mandados para serem tratados com seus familiares, o que era raro acontecer, pois muitos meninos eram oriundos da Roda dos Expostos; portanto, sem pais e parentes, quando muito protegidos por um tutor. Já na Escola Agrícola do Cutim, criada em 1854, foi instalada uma enfermaria para atender aos internos sob a assistência de dois 
escravos treinados pelo médico César Augusto Marques, já que, com muita frequência, os alunos eram atacados por animais peçonhentos ou cortavam-se com facões, enxadas, gadanhos ou outros instrumentos agrícolas utilizados nas aulas de campo, necessitando, assim, de socorro médico de urgência. Os casos mais graves eram transportados em redes para os hospitais de São Luís, ou o diretor pedia ajuda a uma "[...] bezendeira ou dependiam [os alunos] da graça de Deus" (CORRESPONDÊNCIA..., 1866), como reclamava Alexandre Durand $^{11}$, pela falta de assistência médica no estabelecimento.

Por sua vez, a Escola de Aprendizes Marinheiros não dispunha de uma enfermaria nos moldes das demais instituições. Por estar localizada no centro de São Luís, apenas dispunha de um pequeno cubículo, "[...] que oferecia ao enfermo uma visão da Praia do Caju, que ajudava na sua cura”. Essa justificativa foi dada pelo Capitão do Porto José Francisco Pinto, em 1867, para desculpar-se pela não existência de um local adequado na instituição para atender aos enfermos. No relatório do Diretor da Casa dos Educandos Artífices, de 1856, podemos verificar o movimento da enfermaria na instituição.

Quadro 1 - Movimento da enfermaria na Casa dos Educandos Artífices.

\begin{tabular}{|c|c|c|c|c|}
\hline \multirow{2}{*}{ MESES } & \multicolumn{5}{|c|}{ ALTERAÇÕES } \\
\cline { 2 - 5 } & EXISTIAM & ENTRARAM & SAIRAM & FALECERAM \\
\hline Janeiro & 3 & 10 & 8 & - \\
\hline Fevereiro & 5 & 15 & 17 & - \\
\hline Março & 3 & 11 & 10 & - \\
\hline Abril & 4 & 9 & 9 & - \\
\hline Maio & 3 & 10 & 9 & - \\
\hline Junho & 4 & 9 & 5 & - \\
\hline Julho & 8 & 15 & 16 & 1 \\
\hline Agosto & 6 & 10 & 6 & - \\
\hline Setembro & 10 & 2 & 6 & 1 \\
\hline Outubro & 6 & 10 & 10 & - \\
\hline Novembro & 5 & 23 & 13 & \\
\hline Dezembro & 15 & 26 & 24 & 3 \\
\hline TOTAL & 72 & 149 & 133 & \\
\hline
\end{tabular}

Fonte: Casa dos Educandos Artífices do Maranhão - 1859.

Conforme observamos no quadro acima, havia um fluxo constante de alunos que entravam na enfermaria dessa instituição para tratamento de saúde. Entretanto, o número de mortos era pouco expressivo em comparação às entradas, permanências e altas registradas na documentação. Dos três alunos que faleceram, um foi por febre cerebral, outro por doença do

\footnotetext{
${ }^{11}$ Diretor da Escola Agrícola do Cutim, que substituiu Luiz Clemont.
} 
peito e o outro por problemas de bexiga; entretanto, as doenças mais comuns que acometiam os educandos das três instituições eram a febre de quebra-ossos (dengue), as febres intermitentes, as erupções cutâneas, as diarreias e as sarnas. Neste último caso (as doenças da pele), o médico Silva Maia recomendava banhos de mar nas praias da Ponta da Areia ou do Caju, que serviriam para "curar os males do corpo" (RELATÓRIO do doutor..., 1867).

Nesse sentido, chama a atenção o ano de 1853, em que toda a Província do Maranhão foi acometida de epidemia de sarampo, bexiga e varíola, notadamente expressa nas instituições que concentravam o maior número de pessoas, como asilos, quarteis e escolas. A varíola, por exemplo, atingiu de maneira grave e ocasionou a aposentadoria de José Antonio Falcão, que durante 12 anos esteve à frente da direção da Casa dos Educandos Artífíces.

O alferes José Antônio Falcão, como sabeis, foi posto à testa da direção da Casa dos educandos desde que ela foi fundada; mas, infelizmente, acha-se impedido por moléstia, há quase um ano e, segundo me informaram, impossibilitado de continuar a servir sem risco de vida. Este funcionário, a quem se deve a bela educação moral que é dada no estabelecimento, cujo zelo e dedicação no desempenho dos seus deveres tem passado em provérbio, pretende em recompensa dos seus bons e leais serviços de mais de 12 anos, o benefício da aposentadoria [...] (RELATÓRIO..., 1853, p. 16).

Paralelamente à doença desse diretor, o escrivão Basilio Heskett foi acometido de “[...] febres, com aumento no tumor articular do joelho direito, moléstia que se tem tornado crônica e muitas destas alterações há de sofrer [...]” (RELATÓRIO..., 1854), como diagnosticou o médico Silva Maia.

A doença de Antônio Falcão e a do escrivão agravou a crise na organização da Casa dos Educandos, sobretudo com a epidemia de sarampo e varíola, entre outras doenças, como a febre, males nos pulmões e tumores, que atingiram 46 educandos da Casa dos Artífices, 14 da Escola Agrícola do Cutim e 56 da Escola de Aprendizes Marinheiros.

Essas sindicâncias exigiram modificações em toda a estrutura das instituições para alojar os enfermos, passando a ocupar as salas de aula e os espaços das oficinas, para incentivar os cuidados e tratamentos. Como forma de minimizar as condições precárias em que os alunos eram tratados, Eduardo Olímpio Machado, presidente da província, autorizou que aqueles meninos, cujos familiares assim o desejassem, poderiam ser retirados dessas escolas para serem atendidos em seus lares: 
Diz Joana Sofia do Espírito Santo Gomes que tem obtido de Vossa Excelência a graça da admissão, na Casa dos Educandos, de um filhinho da Suplicante. Acha-se este, há tempo, doentinho de tal modo que, apesar do carinhoso tratamento, que ali tem, não há experimentado melhoras. Vem, pois a suplicante requerer a Vossa Excelência licença para ir buscar o dito seu filho e tê-lo por algum tempo em sua companhia até ver se é possível o seu restabelecimento e tornar ao gozo dos benefícios de tão caridoso estabelecimento [...] (RELATÓRIO..., 1853).

A saída dos educandos por motivo de doenças, aliada à falta de trabalho nas oficinas, fez com que muitos não voltassem para a instituição, como Antônio Cyrilo Caldeiras e Mathias Francisco de Abreu, os quais, afastando-se para iniciarem o tratamento médico na casa de familiares, não retornaram mais a Casa dos Educandos Artífices. Esses afastamentos foram relatados por Antonio Maia, no Relatório de 1856:

Há muito se acha restabelecido [Mathias Francisco de Abreu] porque constantemente é encontrado nas ruas desta cidade, até em dias de chuva, trajando com as roupas da Casa [...] parece por isso que se deva recolher ao Estabelecimento [...] acrescendo dizer que semelhante procedimento fere muito de perto a disciplina e a certas disposições regulamentares da Casa, a que todos quantos são educandos se devem sujeitar, o que tem dado lugar a reparo de seus próprios companheiros que o encontram e também a mim, que isso observei quando na tarde do dia 17 do corrente estava com o Corpo dos Educandos formando na rua de Nazareth para acompanhar um enterro.

No ano seguinte, 1857, o quadro das doenças dos enfermos educandos artífices piorou, devido ao forte inverno que atingiu toda a província, a ponto de ser necessário alojá-los em uma propriedade de Antônio Falcão, localizada na Rua da Concórdia, ao lado da instituição, e que resultou na morte de três meninos: Pedro de Alcântara de Moraes, por febre amarela; Afonso Henriques Lages, por febre biliosa; e Francisco Pereira Cardozo, por diarreia, gangrena intestinal e alienação mental. Por outro lado, na Escola Agrícola foram canceladas todas as atividades de campo e diminuídas a refeição dos alunos, especialmente pelos estragos na produção de verduras e legumes, e, principalmente, pela dificuldade de transporte de alimentos para o estabelecimento.

A causa dessas doenças, segundo o cirurgião-mor José Silvestre dos Reis Gomes, podia ser atribuída ao clima da estação. Mas os enfermos achavam-se nas melhores condições 
higiênicas, recebendo a melhor e mais bem combinada alimentação, "[...] sendo certo que nada escapa[va] no que tange ao melhoramento e apreciação do zeloso Diretor do Estabelecimento [Antonio Maia], que por inteira justiça pode ser denominado Pai desvelado" (RELATÓRIO do cirurgião José Silvestre dos Reis, 1855). Ressaltamos que este médico se reportava às condições higiênicas da Casa dos Educandos Artífices, o que não ocorria com a Escola do Cutim, que teve as suas dependências alagadas, e a Escola de Marinheiros, cujo teto desabou, sendo os meninos transferidos de ambas as instituições para o quartel militar.

Para o médico Luiz Miguel Quadros, substituto de José Silvestre dos Reis Gomes, a causa das inúmeras doenças existentes na Casa dos Educandos e na Escola do Cutim era ocasionada por vários fatores, entre eles: a situação dos dormitórios, a precariedade da enfermaria, a inexistência de cloacas, as atividades físicas em excesso, além da localização das instituições, próximas aos apicuns, pântanos, alagadiços e mangues. Quando faz referência à situação precária dos dormitórios, reclamava que os mesmos eram:

Cobertos de telha, sendo baixos e pouco arejados, como são conservam até a alta da noite uma temperatura elevada devido à ação dos raios solares durante o dia; essa temperatura conserva-se ou aumenta durante a noite com o calor natural de muitas pessoas aglomeradas em uma sala fechada, por mais espaçosa que ela seja; além do ar viciar-se pela expiração de muitos indivíduos, o que de certo ponto pode comprometer seriamente a saúde, acresce mais o inconveniente de não serem os dormitórios assoalhados, como convinha, e sim ladrilhados com tijolos, sendo isso por demais nocivo na época das chuvas, visto como a umidade torna-se permanente nos aposentos. Aos levantarem-se os meninos, com o descuido que lhes é natural, pisam descalços, ainda quentes no ladrilho frios e úmido, dali vem a supressão de transpiração, bronquites, reumatismos, febres intermitentes com congestões ou inflamações no fígado e baço; moléstias, estas, que sempre figuram em avultado número nas estatísticas médicas [...] (RELATÓRIO..., 1867).

Para esse médico, uma alternativa para solucionar este problema seria a obrigação dos alunos estarem calçados em tempo integral, evitando intercorrências e possibilitando maior nível de higiene, julgando, por outro lado, a regular atividade de "carpidores-músicos", fator que poderia influenciar no aumento das enfermidades dos meninos da Casa dos Educandos. Ou seja, como forma de o estabelecimento angariar fundos para sua manutenção, a banda de música se fazia presente em todos os enterros, bastando que qualquer interessado pagasse os 
valores determinados pela direção da Casa. Assim, a banda de música chegou “[...] a criar moda nos acompanhamentos de enterro pelos educandos artífices, a tal ponto que, até o pobre esmolava para conseguir esse aparato para o funeral para os seus defuntos [...]", segundo a reclamação de Raimundo Jansen, em 1872.

Em consequência da atividade de "carpidores-músicos", os alunos tinham que marchar muitas vezes em horas impróprias e tocar instrumentos de sopro superiores às suas capacidades físicas, “[...] estafando-se na extensão das palavras, além de esporem-se às intempéries, apanhando aguaceiros quando em estado de transposição abundante [...]" (RELATÓRIO..., 1872). No que se refere à enfermaria, Miguel Quadros criticava a obscuridade e a pouca ventilação do local, embora os medicamentos e a alimentação dos enfermos fossem de boa qualidade e em quantidades precisas; alegando que a falta de cloacas $^{12}$ no interior dessas instituições afetava a higiene e a saúde dos alunos, já que os mesmos se aliviavam nos matos;

Mesmo em dias de chuvas esta prática abusiva continuava causando terríveis e fatais consequências; não pude suportar esta falta por tanto tempo e mesmo a expensas da casa mandei construir dois quartos para o mencionado fim dentro do estabelecimento, sendo um para os educandos maiores e outro para os menores [...] (RELATÓRIO..., 1872).

Nesse sentido, a falta de cloacas agravava-se quando os alunos estavam enfermos, pois tinham que recorrer a "penicos" para suas "evacuações ventrais", que "infestavam as coxias de mau cheiro". À noite, eram espalhados vários penicos para os alunos "mijarem”, e quando cheios, usavam o chão de terra batida, fazendo com que o cheiro forte de "mijo" fosse sentido em todos os ambientes; sem contar que as crianças menores ainda traziam o hábito de “mijarem nas redes”, como explicava Raimundo Jansen Lima (1872).

Em relação à dieta dos doentes, conforme as orientações médicas, estas deveriam ser servidas em seis porções diárias, sendo a primeira às seis horas da manhã, composta por café, pão branco e um caldo de galinha ou de carne; às 10 horas, um copo de leite ou chá; no almoço, carne verde com verduras, arroz branco e farinha seca; às 14 horas, chá da índia com pão e uma fruta, como abacaxi ou laranja; no jantar, arroz branco com frango assado e batata branca ou doce; e às 21 horas, um copo de leite com canela e/ou mingau de araruta, arroz ou de fubá de milho. Para os doentes cujas moléstias eram excepcionais, ficava a critério do

\footnotetext{
${ }^{12}$ Cano de limpeza das imundices da cidade; sentina (MORAES, Antônio de. Dicionário de Língua Portuguesa. Lisboa: [s.n], 1831.v. 1).
} 
médico a concessão de doces, cevada, sagu, araruta, macarrão, ervas, frutas, carneiro, peixe e geleias. Essas dietas ficavam penduradas à cabeceira da cama do doente e deviam ser obedecidas pelo enfermeiro, que também era responsável pela aplicação dos medicamentos nas horas determinadas pelo médico, inclusive à noite.

Como forma de evitar a proliferação de doenças, os enfermos eram proibidos de sentarem ou deitarem na cama de outro, andarem descalços pela enfermaria e/ou falarem em voz alta. Esses casos eram punidos “[...] com diminuição nas dietas, reduzidas a três caldos simples ou com castigos que [podiam] ser aplicados aos educandos e não prejudicando ao castigado, em atenção à moléstia que padecer [...]” (REGULAMENTO, 1843, p. 4).

Os alunos com doenças venéreas eram isolados dos demais e tinham suas roupas pessoais e de cama trocadas e escaldadas todos os dias, recebendo de acordo com o tipo da enfermidade "unguentos nas partes acometidas pela doença" (RELATÓRIO..., 1887). Chamou-nos atenção à expressão "nas partes acometidas pela doença", o que nos leva a pensar que os alunos poderiam ser acometidos de doenças venéreas de várias naturezas, oriundas de relações hetero ou homossexuais.

Ainda com relação à dieta alimentar, no período de 1873 a 1881, houve a necessidade de recursos extras dos cofres provinciais para atender ao grande número de educandos e funcionários dos estabelecimentos acometidos de sarampo e beribéri; essas epidemias atingiram a província do Maranhão, como divulgado no jornal $O$ Domingo, de 18 de fevereiro de 1876:

O beribéri tem feito cobras e lagartos, que é um Deus nos acuda; estabeleceu entre nós despótica sede, e no seu reinado arbitrário e absoluto, tem proscrito e degradado a torto e a direita. Nas corporações, exerce mais que em outra qualquer parte o seu predomínio. Os seminários, colégios, quartéis, e o estabelecimento dos educandos tem pago um triste e enorme tributo a tão fatal moléstia (O DOMINGO, 1876, Grifo nosso).

Como forma de tratamento, os educandos eram enviados para a praia da Ponta d'Areia, onde deviam banhar-se três vezes ao dia, pela manhã, ao meio-dia e no final da tarde. Aqueles que apresentavam melhoras seguiam no vapor Gomes de Castro para a cidade de Itapecuru, onde o tratamento era mais barato.

Além dos banhos de mar, César Marques e Silva Maia indicavam os exercícios físicos, como a ginástica, a natação e a corrida: a ginástica e a corrida praticadas a partir dos 12 anos; a 
natação desde os sete anos de idade, em rios de águas limpas e calmas, ou na praia, quando a maré estivesse baixa. Para Gondra (2007, p. 534):

A questão do corpo, do movimento, dos exercícios ou da ginástica é uma preocupação que ocupa lugar privilegiado na agenda médica fazendo com que, ao tratar da educação escolar, também, inclua esse tema como um dos aspectos a ser observado no rol de recomendações por eles estabelecidas, de modo a produzir um colégio, alunos, professores e mestras higienizados.

Como forma de contribuir com a saúde dos desvalidos, Martins Hoyer, um negociante dinamarquês situado no mercado ludovicense, importou da Europa aparelhos de ginástica e os doou às três instituições. A partir de então, a atividade física foi incorporada no cotidiano dos educandos maiores de 15 anos, como forma de mantê-los fortes e robustos para o trabalho na marinha, no campo ou como pedreiros, marceneiros, carpinteiros e outras profissões que exigiam mais do corpo do que do espírito. A partir de então, essas instituições passaram a incorporar nos seus critérios de ingresso parecer de capacidade física e mental, emitidos pelos médicos da Santa Casa da Misericórdia, de modo a evitar a presença de incapazes para as artes mecânicas, agrícolas e da marinha, como o

[...] educando Esperidião do Sacramento Silva foi recebido neste Estabelecimento há cinco meses, por ordem do Presidente da Província de 11 de julho do ano corrente, e durante todo esse tempo tem estado constantemente doente, em consequência de ter o terrível vicio de comer terra, acrescentando agora o de comer cabelo que os arranca de sua própria cabeça; e como ele atualmente exista em um estado incurável, portanto, tem sido infrutíferos todos os meios para empregados pra o seu curativos [...] vicio tão arraigado este, que só a morte o fará deixar, pelo que acho prudente levar ao conhecimento do Exmo. Sr. Presidente da Província, a fim de mandar entregar a quem consentir em tal vicio, escusando o estabelecimento sofrer o desgosto de o ver morrer ele o autor da sua morte [...] (RELATÓRIO...,1855).

Outro aluno que não oferecia meios para o desenvolvimento físico era Felipe Vieira de Souza, por ser surdo-mudo. Ao ingressar na Escola de Aprendizes Marinheiros por ordem do Presidente da Província, Olimpio Machado foi transferido para a Casa dos Educandos Artífices com a justificativa de que o seu problema não permitia servir à Marinha. Entretanto, 
Antonio Maia, ao receber Felipe, enviou correspondência a esse presidente, demonstrando a sua indignação ao afirmar que:

[...] esse educando mandado por V. Excelência, não pode aprender as primeiras letras e nenhum oficio mecânico, nada escuta, nada fala. $\mathrm{O}$ que fazer com ele, a não ser gastar os poucos recursos desta casa. Mas, por ser um protegido de Vossa Excelência a única coisa que posso fazer para mantê-lo na Casa sob a proteção de Vossa Excelência e que ajude no serviço de limpeza em troca de comida e um bom abrigo (RELATÓRIO..., 1855).

Os alunos que apresentavam capacidade física, moral e intelectual, de acordo com as regras impostas pelos dispositivos legais, eram estimulados com premiações em forma de medalhas, roupas e, quando os recursos permitiam, alguns tostões. Na contramão, aqueles que não atendiam às regras disciplinares e não se convertiam em corpos dóceis, eram punidos pela maquinaria legal imposta pelos diretores das instituições e as suas estratégias de vigilância hierarquizadas. Essas punições variavam desde a repressão em frente aos demais internos, até a suspensão de uma das refeições ou prisão; nos casos mais graves e reincidentes, a expulsão da instituição era inevitável.

O exercício corporal servia, também, como uma espécie de "vitrine" da saúde dos alunos da Casa dos Educandos e dos Aprendizes Marinheiros, especialmente quando estes apareciam publicamente, descendo e subindo as ladeiras de São Luís, “[...] carregando dos mercados sacas de arroz, paneiros de farinha, galinhas e carnes, sob seus ombros desnudos de meninos-homens ${ }^{13}$ " (CORRESPONDÊNCIA..., 1867). Em relatório do professor de armas dos aprendizes da marinha, João Batista de Oliveira Guimarães, enviado ao presidente da Província, Gomes de Castro, ele afirmou textualmente que:

Os exercícios físicos praticados nesta instituição têm levando aos meninos a uma robustez e tenacidade do corpo. Ao saírem às ruas, sempre acompanhados de outros aprendizes chamam atenção por onde passam, o que deixa ver o quão são bem tratados nesta casa mantida pelos cofres do governo. Por isso, precisamos mandar construir maior espaço para a prática dessas atividades [físicas] (RELATÓRIO..., 1871).

\footnotetext{
${ }^{13}$ Expressão utilizada pelo Secretário do Capitão do Porto, Raimundo de Souza Barradas, e professor da Escola de Aprendizes Marinheiros, quando se reportava aos alunos com mais de 16 anos.
} 
Se por um lado esses corpos robustos e tenazes causavam admiração por onde passavam, certamente também poderiam, no interior desses estabelecimentos, receberem olhares e despertarem desejos entre seus companheiros. Todavia, como dito anteriormente, aspectos referentes à conduta sexual dos aprendizes são lacunares na documentação pesquisada, aparecendo tão somente de maneira fragmentada nos ofícios enviados pelos diretores das instituições aos presidentes de província e nos relatórios médicos. Entretanto, esses indícios são relevantes por possibilitarem a compreensão de como ocorria o tratamento das enfermidades e o controle dos desejos corporais dos meninos recolhidos em instituições educativas no Maranhão, nos oitocentos.

\section{Corpos em movimento: o comportamento sexual dos meninos educandos}

O primeiro caso de "[...] contravenção da moralidade religiosa e moral empregada na Casa [...]” dos Artífices (RELATÓRIO..., 1843) e que aparece nos documentos, refere-se ao educando Avelino Antunes Ribeiro. As informações são importantes por se tratarem de homossexualidade e masturbação, consideradas na época doenças físicas e degeneradoras do espírito, segundo o médico da Casa, Luiz Miguel Quadros, constituindo-se em perigos para o desenvolvimento físico, na medida em que, “[...] debilitado pelo desperdício de energia, o menino masturbador não [era] verdadeiramente viril e nem [seria] jamais", como afirma Jablonka (2013, p. 63). Portanto, nessas instituições, "a vigilância não deve[ria]descansar um só instante" (JABLONKA, 2013, p. 63).

Para Antônio Falcão, Avelino Ribeiro devia ser expulso da instituição de ensino, não só por "apresentar distúrbios graves de personalidade, [e ser] ignorante e desviado", como também por ter o vício de masturbar-se várias vezes ao dia, pelos "cantos da Casa" (RELATÓRIO..., 1843), apesar do forte controle exercido pelos agentes de vigilância. Dessa forma, a sua demissão devia ser imediata, antes que "[...] contaminasse este estabelecimento de recolhimento de desvalidos [...]" (RELATÓRIO..., 1854). Assim, além de:

[...] masturbar-se como louco, adota a induzir os pequeninos a masturba-lo ou fazê-lo de parceria com outros do seu tamanho e idade (como já tem feito, e sofrido castigos sem que se emende), e assim introduzir aqui um vício que tanto tem de indigno, como de prejudicial à robustez que devem ter estes jovens que se destinam aos ofícios mecânicos [...] (RELATÓRIO..., 1854). 
Essa atitude de Avelino ganhou maiores proporções quando passou a "[...] ter [relações sexuais] com outros educadores nas suas redes ou fugindo as noites para os matos atrás da Casa, para se deitarem como se fossem homem e mulher [...]" (RELATÓRIO..., 1854). Como forma de coibir essa prática do aluno, o diretor, por diversas vezes, amarrava as suas mãos, trancava-o na prisão do estabelecimento, ou o repreendia publicamente frente aos demais alunos, mas “[...] nada disso o emenda[va]” (RELATÓRIO..., 1854).

Um caso de homossexualidade na Casa, com indícios de pedofilia, envolveu o capelão Luiz Nunes Clarindo Guedes, o qual, segundo Antônio Falcão, apresentava "conduta sexual desviante", o que o levava ao descrédito e à rejeição dos alunos sobre suas atividades religiosas, como relatou esse diretor ao Presidente da Província:

O lugar do Capelão deste estabelecimento entendo que deverá ser ocupado por um sacerdote circunspeto, isto é, de boa moral e exemplar conduta, pois em sua posição e deveres a cumprir são os mais importantes, conforme determina o respectivo regulamento. Infelizmente o atual Capelão Padre Luiz Nunes Clarindo Guedes, moço e por isso talvez ainda, fogoso nas paixões mundanas, entregase em demasia a sociatas [sic] e ao vício da cópula, pelo que tem apresentado um papel vergonhoso a ponto de às vezes não poder celebrar, e retirar-se do altar, como ainda aconteceu por ocasião da Missa de Domingo, 30 do mês próximo passado, isto além de outras circunstâncias e faltas que entendo deixar de aqui mencionar porque as tenho revelado. Em vista, pois, do expedido vou respeitosamente ante V. Exa. solicitar sua destituição de Capelão desta Casa mesmo porque nenhuma consideração e força moral goza entre os educandos, a ponto de muitos destes pedirem-me, com insistência, dispensa de se confessarem ou estarem a sós com ele. Os meios persuasivos que tenho empregado têm sido infrutíferos e por isso humildemente entendo que é indispensável sua demissão, a bem da disciplina e moralidade dos educandos [...] (RELATÓRIO..., 1851, grifo nosso).

As relações sexuais praticadas entre homem e mulher eram também consideradas uma atitude desviante, no entanto tolerável aos meninos maiores de 17 anos, pois servia para "aliviarem a natureza" masculina, como defendia Antônio Falcão. Todavia, mesmo compreendendo "as necessidade dos meninos crescidos", Antônio Maia julgava que a sua prática deveria ser controlada para não tirar deles as responsabilidades pelos ofícios mecânicos e "manchar o nome da Casa que os acolhia". No caso dos aprendizes marinheiros, Raimundo de Souza Barradas afirmava que os "meninos-homens", ao regressarem de suas 
missões pelos rios do Maranhão, depois de descansarem da longa jornada, tinham licença para saírem no começo da noite, após a ceia, e voltarem às 21 horas, para que "[...] pudessem descarregar suas energias com madames que ofereciam esses serviços" (CORRESPONDÊNCIA..., 1869). Como exemplo, eram registrados na documentação os aprendizes Hygino Antônio Ramos e Bernardino do Rego Barros.

Um dos casos de desvio do comportamento sexual era o educando Antônio José da Costa, 21 anos, “[...] um ser extravagante com as meretrizes, que não há consideração que lhe obste a procurá-las, ainda com transtorno para serviço deste estabelecimento [...]" (RELATÓRIO..., 1847). Outro exemplo era o educando Francisco da Silva, 22 anos, que pouco se submetia ao trabalho e às normas, pois todas as vezes que saía para banhar-se próximo ao estabelecimento, demorava-se mais do que o necessário e, mesmo advertido, continuava a cometer o mesmo ato indisciplinar; “[...] o pior é que estimulava outros educandos a cometerem o mesmo ato [...]" (1847). E, ainda, que:

Tem se tornado o mencionado educando um perfeito desleixado depois que chegou à idade da puberdade, e todo o seu cuidado e andar sempre ocupado com meretrizes e por essa causa de tudo o mais se esquece, de nada mais cuida, com o cuidado que deve e sabe cuidar, esquecendo até da Casa e do modo por que nela se deve conduzir, o que torna improvável a sua continuação como educando (RELATÓRIO..., 1847)

Daí a sugestão de Antônio Falcão de que ele fosse demitido e encaminhado para o corpo da tropa, onde poderia seguir as normas militares e vir a se constituir num bom oficial. O motivo do "sumiço" do educando Francisco era para se encontrar com as mulheres que moravam atrás da Casa dos Educados, dispostas a atender aos desejos carnais do jovem em troca de alguns tostões.

Para Antônio Falcão, atitudes como essas levariam à sociedade a ter uma imagem negativa em relação ao Estabelecimento, pelo fato de os alunos saírem das dependências da escola para irem ao encontro de mulheres que residiam numa capoeira, situada ao lado norte da Casa dos Educandos, onde permaneciam às vezes o dia inteiro, principalmente os mancebos que tocavam na banda de música. Ou ainda quando realizavam encontros furtivos com prostitutas nas festas em que tocavam, o que ocasionava o aparecimento de doenças venéreas, como aconteceu com o educando Alberto Manoel Bacharias, 24 anos, acometido de cancro mole. De acordo com Antonio Maia, isso era o resultado dos “[...] atos libidinosos e do 
descaramento dos mancebos que na puberdade perdem a disciplina e a moral para correrem à procura de aliviarem suas naturezas com mulheres libidinosas e de vida fácil [...]" (RELATÓRIO..., 1849).

Se os aprendizes marinheiros e os educandos artífices mantinham relações entre si ou com mulheres, os da Escola do Cutim, pela distância do centro da cidade, não gozavam da mesma estratégia para aliviarem seus desejos carnais. Estes sujeitos-adolescentes exerciam um comportamento sexual atípico, que chamou atenção de Alexandre Durand, ao chegar à instituição como diretor. Durand julgava "[...] perniciosa, primitiva, e que merecia ser punida com a expulsão do educando [...]", referindo-se, neste caso, às relações com os animais da própria Escola. Para ele, os educandos maranhenses saíam pelas “[...] noites em bando, à procura das bestas, éguas, cabras e tudo quanto é animal para cruzarem como se fossem da mesma espécie" (CORRESPONDÊNCIA ..., 1866).

De modo a evitar que os educandos maiores (os mancebos) pudessem estimular a curiosidade e o desejo carnal dos meninos de menor idade, ou quiçá, de serem abusados sexualmente por aqueles, Silva Maia recomendou ao diretor da Escola de Marinheiros e da Casa dos Educandos que fossem divididos por seções de acordo com a faixa etária e o grau de comportamento moral, físico e intelectual dos mesmos. Desse modo, acreditava ser possível evitar um vício que estava impedindo o crescimento das crianças, no caso da masturbação, e também contribuindo para conter ou evitar o constante e crescente aumento de doenças venéreas entre os que já “[...] tinham dentre de si a ardência da carne [...]” (RELATÓRIO do doutor Silvia Maia..., 1867).

\section{Conclusão}

Este texto, mesmo limitado pelas fontes, possibilitou tecermos as diferentes e diversas formas de tratamento médico-sanitário na Casa dos Educandos Artífices, na Escola Agrícola do Cutim e na Escola de Aprendizes Marinheiros, três instituições representativas de atendimento a crianças desvalidas do sexo masculino no Maranhão, no século XIX. Além disso, os dados levaram-nos a conhecer as estratégias dos alunos para "aliviarem" os seus desejos da carne, pela masturbação ou pelas relações sexuais de natureza distintas, apesar do forte e militar esquema de vigilância e de controle sobre as atividades cotidianas dos internos. Tanto o controle como as formas de regulação atingiam todas as formas e os modos de comportamento dos alunos, em especial sobre as paixões, os desejos carnais dos "meninoshomens". 
Por conseguinte, como resultado dessas relações, os educandos eram acometidos de inúmeras "doenças do mundo" (RELATÓRIO..., 1867), como a sífilis, o cancro e os bubões venéreos. Essas doenças eram tratadas nas enfermarias dos estabelecimentos ou nos hospitais de São Luís, como o Militar e o da Santa Casa da Misericórdia; embora pareça, pela documentação levantada, que ser vítima de algum padecimento venéreo era mais que um perigo para a saúde do jovem educando, servia como uma demonstração de virilidade e como um ritual de passagem obrigatório, natural e necessário entre a infância e a adolescência, ou como uma forma de "tornar-se macho", conforme afirma Baubérot (2013).

Por outro lado, como forma de manter o estado sanitário e a higiene dos educandos de outras enfermidades, foi criada uma rede de tratamento que envolvia médicos, enfermeiros e cuidadores dos doentes; além de se fazer necessária a melhoria das condições físicas das instituições, de modo a garantir a sanidade física, mental e intelectual dos aprendizes nas artes agrícolas, mecânicas e aquelas atinentes às práticas das embarcações marítimas.

Esperamos que este trabalho contribua para outros estudos no campo da História da Educação, de modo que possamos compreender as diversas formas de tratamento das enfermidades e do controle dos desejos sexuais dos meninos(as) pobres e desvalidos(as) nas instituições educativas brasileiras, em especial no Maranhão imperial.

\section{Referências}

BAUBÉROT, Arnaud. Não se nasce viril, torna-se viril. In: CORBIN, Alain; COURTINE, Jean-Jacques; VIGARELLO, Georges. História da sexualidade: virilidade em crise-séculos XX-XXI. Petrópolis: Vozes, 2013.

CORRESPONDÊNCIA de Alexandre Durand [Diretor da Escola Agrícola do Cutim] ao presidente da Província Lafayette Rodrigues Pereira, em 1866.

CORRESPONDÊNCIA de José Francisco Pinto [Capitão do Porto] ao presidente da Província Franklin Américo de Menezes Doria, em 1867.

CORRESPONDÊNCIA de Raimundo de Souza Barradas [Secretario do Capitão do Porto], ao vice-presidente da Província José da Silva Maia, 1869.

FARGE, Arlette. As luzes e a virilidade inquieta. In: CORBIN, Alain; COURTINE, JeanJacques; VIGARELLO, Georges. História da sexualidade: a Invenção da virilidade da Antiguidade às Luzes Petrópolis: Vozes, 2013.

FOUCAULT, Michel. História da sexualidade: o uso dos prazeres. 12. ed. Rio de Janeiro: Edições Graal, 2007. 
FOUCAULT, Michel. Microfísica do poder. Rio de Janeiro: Forense, 2004. Não está citado. FOUCAULT, Michel. Os anormais. São Paulo: Martins Fontes, 2002.

GONDRA, José G. Medicina, higiene e educação escolar. In: Lopes, E.; FARIA FILHO, L. M.; VIEGA, Cyntia Greive. 500 anos de educação no Brasil. Belo Horizonte: Autêntica, 2007.

HAROCHE, Claudine. Antropologia da virilidade: o medo da impotência. In: CORBIN, Alain; COURTINE, Jean-Jacques; VIGARELLO, Georges. História da sexualidade: virilidade em crise-séculos XX-XXI. Petrópolis: Vozes, 2013.

JABLONKA, Ivan. A infância ou a "viagem rumo à virilidade". In: CORBIN, Alain; COURTINE, Jean-Jacques; VIGARELLO, Georges. História da sexualidade: virilidade em crise-séculos XX-XXI. Petrópolis: Vozes, 2013.

MATTHEWS-GRIECO, Sara F. Corpo e sexualidade na Europa no Antigo Regime. In: MOREIRA, Adailson. A homossexualidade no Brasil no século XIX. Bagoas, v. 7, p. 253 $279,2012$.

O DOMINGO, de 18 de fevereiro de 1876.

REGULAMENTO da Casa dos Educandos Artífices, 1843.

RELATÓRIO de João Batista de Oliveira Guimarães [Professor de armas da Escola de Aprendizes Marinheiros] ao presidente da Província Franklin Américo de Menezes Doria, em 1867.

RELATÓRIO de José Antonio Falcão ao presidente da Província do Maranhão Jerônimo Martiniano Figueira de Mello, em 1843.

RELATÓRIO de José Antonio Falcão, Diretor da Casa dos Educandos Artífices ao presidente da Província Joaquim Franco de Sá, em 1847.

RELATÓRIO de José Antonio Falcão, Diretor da Casa dos Educandos Artífices ao presidente da Província Eduardo Olimpio Marchado, em 1851.

RELATÓRIO do cirurgião José Silvestre dos Reis, ao Diretor da Casa dos Educandos Artífices Antonio Maia, 1855.

RELATÓRIO do doutor Silvia Maia, médico da Santa Casa da Misericórdia ao Diretor da Casa dos Educandos Artífices Antonio Maia, em 1867.

RELATÓRIO do Sr. Antonio Maia, diretor da Casa dos Educandos Artífices encaminhado a Vossa Excelência Eduardo Olimpio Machado, presidente da Província do Maranhão, em 1853.

RELATÓRIO do Sr. Antonio Maia, diretor da Casa dos Educandos Artífices encaminhado a Vossa Excelência Eduardo Olimpio Machado, presidente da Província do Maranhão, em 1854. 
RELATÓRIO do Sr. Antonio Maia, diretor da Casa dos Educandos Artífices encaminhado a Vossa Excelência, Eduardo Olimpo Machado, presidente da Província do Maranhão, em 1855 .

RELATÓRIO do Sr. Antonio Maia, diretor da Casa dos Educandos Artífices encaminhado a Vossa Excelência, Benvenuto Augusto de Magalhães Taques presidente da Província do Maranhão, em 1857.

RELATÓRIO do Sr. Antonio Maia, diretor da Casa dos Educandos Artífices encaminhado a Vossa Excelência Manoel Jansen Ferreira presidente da Província do Maranhão, em 1867.

RELATÓRIO do Sr. José Antônio Falcão, diretor da Casa dos Educandos Artífices encaminhado a Vossa Excelência João Antonio de Miranda, presidente da Província do Maranhão, em 1842.

RELATÓRIO do Sr. Raimundo Jansen Lima, diretor da Casa dos Educandos Artífices encaminhado a Vossa Excelência, Manoel Jansen Pereira, vice-presidente da Província do Maranhão, em 1867.

RELATÓRIO do Sr. Raimundo Jansen Lima, diretor da Casa dos Educandos Artífices encaminhado a Vossa Excelência, José da Silva Maia presidente da Província do Maranhão, em 1872.

RELATÓRIO do Sr. Raimundo Jansen Lima, diretor da Casa dos Educandos Artífices encaminhado a Vossa Excelência, José Bento de Araújo presidente da Província do Maranhão, em 1872.

REVENIN, Regis. Homossexualismo e virilidade. In: CORBIN, Alain; COURTINE, JeanJacques; VIGARELLO, Georges. História da sexualidade: o triunfo da virilidade - o século XIX. Petrópolis: Vozes, 2013. 